\title{
Sexual transmission of hepatitis B virus: Epidemiological considerations and implications for control with vaccine
}

FRANKLYN N JUDSON, MD

\begin{abstract}
FN Junson. Sexual transmission of hepatitis B virus: Epidemiological considerations and implications for control with vaccine. Can J Infect Dis 1991;2(Suppl A):3A-8A. Prior to the acquired immune deficiency syndrome (AIDS) epidemic, more than $50 \%$ of the new hepatitis $B$ virus infections in the United States and Canada were sexually transmitted, approximately one-quarter by heterosexual men and women and one-third by homosexual men. The percentage of hepatitis $B$ virus infections attributable to heterosexual transmission in developing and developed countries of Asia is unknown, but is probably proportionate to the percentage of the population which escapes perinatal and early childhood infection. In homosexual men of developed countries, fear of AiDs has led to dramatic reductions in high risk sexual behaviour and hence in the incidence of hepatitis $B$ virus infection. Specific interventions designed to prevent sexual transmission of human immunodeficiency virus (eg, testing for infection status and counselling, choosing partners carefully, avoiding prostitutes, use of condoms, and diagnostic and treatment services for other sexually transmitted diseases) should further reduce hepatitis $B$ virus sexual transmission in men and women. Eventually, however, hepatitis B virus vaccination programs will need to be considered for all countries. They should take into account regional epidemiology, vaccination cost-benefit, and program goals such as prevention of perinatal infection, sexually transmitted acute hepatitis, and/or cirrhosis and hepatic cancer, as well as containment versus eradication of the virus. If cradication is the goal, the only valid strategy is universal vaccination of infants or young adolescents - or both.
\end{abstract}

Key Words: $A D S$, Control strategies, Hepatitis 13 , Sexually transmitted diseases, Sexual transmission, Vaccine

\section{Transmission sexuelle de l'hépatite B: Considérations et implications épidémiologiques de la vaccination prophylactique}

RESUME: Aux États-Unis et au Canada, avant l'êpidémie de syndrome d'immunodéficience acquise (SIDA), plus de la moitié des nouvelles infections par le virus de l'hépatite B (HBV) étaient transmises sexuellement - près d'un quart par les hétẻrosexuels des deux sexes et un tiers par les hommes homosexuels. Le pourcentage d'infections à HBV de source hétérosexuelle dans les pays en voie de développement et dans les pays développés d'Asie n’est pas connu.

Liaison Medical Officer, Global Programme on Ans and Sexually Transmitted Diseases Programme, World He'allh Organization Correspondence and reprints: Dr FN Judson. CDS/VDT, World IIealth Organization. 1211 Geneva 27. Switzerland. Telephone (+41-22) 791-4142. Far $(+41-22) 791-0746$ 
mais il est probablement proportionnel au pourcentage de la population qui èchappe à l'infection acquise de façon périnatale et au cours de la première enfance. Dans les pays développés, la crainte du SIDA a entraînè une réduction notable des pratiques homosexuelles à haut risque, laquelle se traduit par une baisse dans l'incidence des infections à HBV. Les interventions particulières visant à prévenir la transmission sexuelle du virus de limmunodéficience humaine - dépistage et counselling, choix prudent des partenaires, exclusion des prostitué(e)s, usage des prêservatifs, services diagnostiques et thérapeutiques relatifs aux autres maladies vénériennes - devraient encore contribuer à réduire la transmission sexuelle du HBV chez l'homme et la femme. Eventuellement, toutefois, tous les pays devront envisager la mise sur pied de programmes de vaccination anti-hépatite B. Ces campagnes devraient tenir compte de l'épidémiologie régionale, des facteurs coûts-bênéfices et des objectifs de la vaccination: prêvention de l'infection périnatale, hêpatite aiguë transmise sexuellement, et/ou cirrhose et cancer du foie. Viseront-elles à contenir l'infection à HBV ou à l'éliminer? Si l'éradication du virus est l'objectif final, la seule stratégie valable est la vaccination systématique des enfants, des jeunes adolescents, ou des deux groupes.

$\mathrm{T}$ HIS PAPER REVIEWS THE EVOLUTION OF THE understanding of hepatitis B as a sexually transmitted infection and the implications the current understanding holds for the design and implementation of control programs with hepatitis B vaccine in developed countries. The role of sexual transmission in the overall epidemiology of hepatitis B will be emphasized, as well as the impact of the acquired immune deficiency syndrome (AIDS) epidemic on homosexual men with respect to sexual behaviour, the incidence of hepatitis $B$, the cost effectiveness of vaccine, prior experience with efforts to deliver vaccine to individuals and groups at high risk of infection, and finally, vaccine strategies to eradicate hepatitis B virus infections. A more complete discussion of heterosexual activity as a risk factor in the transmission of hepatitis $B$ virus can be found in a companion article by Alter (1).

With the discovery of specific serological markers for infection with hepatitis B virus in the late 1960s and early 1970s, it became possible to distinguish hepatitis B from other types of hepatitis and thus to define its epidemiology and natural history. Quickly discarded was the widely held misconception that 'serum' or 'long incubation' hepatitis (terms used before 'hepatitis B') was caused by a virus-like agent which had become inexplicably locked up in the human blood system, exclusively dependent for its survival on percutaneous transmission through medical procedures, transfusion of blood products and other effectors of blood-to-blood contact.

A rapidly expanding epidemiological literature indicated that hepatitis B virus was being maintained worldwide in human populations primarily by person-to-person transmission during intimate physical contact. Intimate physical contact was, however, a very broad common denominator and soon came to include such diverse experiences as contact between mother and neonate during delivery, anal-genital intercourse between homosexual men, nonsexual physical relations between infected children and their mothers and siblings, and a multitude of types of 'sexual' contact between heterosexual men and women.

\section{SEXUAL TRANSMISSION OF HEPATITIS B VIRUS}

To examine the role of sexual contact in hepatitis $\mathrm{B}$ virus transmission, the earliest studies in the 1970s compared frequencies of hepatitis B virus serological markers in populations that differed from each other as to numbers or types of sexual partners. In 1973, Jeffries et al (2) published data on the prevalence of hepatitis B surface antigen (HBsAg) among 1650 patients attending the venereal disease department at St Mary's Hospital (London, United Kingdom). These investigators were among the first to document an excess of HBsAg in homosexual men and men of non-European origin, but argued against heterosexual venereal spread since only two of 553 women $(0.36 \%)$ and one of 520 heterosexual European men $(0.19 \%)$ were positive for HBsAg.

At about the same time Fulford et al (3) of the Middlesex Hospital (London, United Kingdom) reported similar prevalences of HBsAg among venereal disease clinic patients. In addition, they studied antibodies to HBsAg (anti-HBs) using the relatively insensitive immunodiffusion test and observed that heterosexual women with three or more sexual partners were significantly more likely to have anti-HBs than were women with zero to two partners $(\mathrm{P}<0.01)$. It was not stated whether the two groups were matched for age and ethnicity. Inexplicably, rates of anti-HBs positivity among heterosexual men did not depend on numbers of sexual partners.

In 1975. Szmuness et al (4) conducted a retro- 
spective review of the role of sexual behaviour in the spread of hepatitis B infection and identified a significant excess (17.9\% versus $7.3 \%)$ of $\mathrm{HBsAg}$ or anti-HBs among heterosexual men and women who attended venereal disease clinics compared to a control group of healthy adult blood donors. This excess changed only slightly when standardized for sex, age or ethnicity. Although female prostitutes would seem to be an obvious group in which to test further the hypothesis of heterosexual transmission of hepatitis B virus, prostitutes vary in hepatitis B virus risk factors other than sexual behaviour, and studies have produced conflicting results.

By the late 1970 s efforts to understand better sexual transmission of hepatitis B virus had shifted to homosexual men who typically had relatively large numbers of sexual partners and high rates of hepatitis $B$ as well as the more traditional sexually transmitted infections. They culminated in the Centers for Disease Control (CDC) multicentre (San Francisco, Denver, Chicago, Los Angeles and St Louis) studies of factors related to the prevalence (5) and incidence of hepatitis B virus infections in urban homosexual men and the toxicity, immunogenicity and efficacy of hepatitis B vaccine (6). Many men who participated in these studies during 1978-81 either continued in or later joined cohorts which made extremely valuable contributions to the essential understanding of the epidemiology and natural history of human immunodeficiency virus (HIV) infection, as well as of the long term immunogenicity and efficacy of hepatitis $B$ virus vaccine (7).

It was learned that within the first year of having regular homosexual activity more than $15 \%$ of men became infected with hepatitis B virus, and that by 10 years the cumulative attack rate was nearly $75 \%$ (5). Later testing of frozen sera for antibodies to HIV (a technique known as seroarcheology) indicated that in San Francisco and Denver the annual incidence of both hepatitis $B$ virus and HIV infections was between 15 and $20 \%$ for the period $1980-82$.

The sexual practices most strongly associated with hepatitis B virus infection in the prevalence and incidence studies were active oral-anal and passive anal-genital intercourse. Because most prior research, including ingestion of fecal extracts by human volunteers and testing of feces for HBsAg, had failed to implicate feces as a source of hepatitis B infection (8), these findings were unexpected. The apparent contradiction was partially resolved in a study by Reiner et al (9) in which 22 homosexual men with hepatitis B virus infection were tested for the presence of HBsAg on gingival and anorectal mucosa and in feces and semen.
Thirteen of 22 men (59\%) were found to have asymptomatic rectal lesions consisting of punctate bleeding points, and $77 \%$ of swabbed specimens from these lesions, $62 \%$ from feces, $59 \%$ from rectal mucosa, and 50\% from anal canal mucosa contained HBsAg. HBsAg was also found in $91 \%$ of gingival swab specimens and $87 \%$ of semen specimens. Thus, exposure to infectious virus in the presence of oral, rectal and/or urethral mucosal defects would establish a setting for de facto parenteral transmission of hepatitis B virus among homosexual men.

The risk of infection following a single specific type of sexual exposure has never been determined for either homosexual men or heterosexual men and women. in whom it is still unclear whether vaginal intercourse is the primary or predominant mode of transmission. It has been well demonstrated, however, that female sexual partners of men with acute hepatitis B who were followed for three to 12 months after exposure experienced a minimal risk of infection of 20 to $27 \%$, and that the cumulative attack rate for homosexual men, and heterosexual men and women repeatedly exposed to hepatitis $B$ virus, is very high (10).

With the marketing in 1982 of an effective and safe vaccine against hepatitis $B$ it became increasingly important to control strategies to determine more accurately the true incidence of hepatitis B virus infections in industrialized countries as well as the fractions attributable to the different risk factors. This has been partially accomplished by the CDC's four-county (Jefferson, Alabama; Denver, Colorado; Pinellas, Florida; and Pierce, Washington) sentinel surveillance system for viral hepatitis which has been operating continuously since 1981 (11). During the $1982-83$ period, the early years of the AIDS epidemic, homosexual activity accounted for nearly one-third of all cases of hepatitis B with a known source, and heterosexual activity for more than 25\%. Thus the means of transmission for a majority of cases of hepatitis B in the United States and presumably in Canada appeared to be sexual, invoking priority attention of control programs.

The percentage of hepatitis $B$ virus infections attributable to heterosexual transmission in developing countries and in developed countries of Asia such as Japan is unknown, but is probably proportionate to the percentage of the population which escapes perinatal and early childhood infection. However, even where the fraction attributable to sexual transmission is small, the burden of sexually transmitted hepatitis B may be high compared with developed countries owing to the much higher overall prevalence and incidence rates. 


\section{VACCINE STRATEGIES TO CONTROL HEPATITIS B VIRUS}

With these epidemiological considerations in mind, as well as the profound impact of the AIDS epidemic on high risk groups and their sexual behaviour, several vaccine-oriented strategies to control sexually transmitted hepatitis B will be reviewed, emphasizing the rapidly changing situation in developed countries.

The ultimate control of hepatitis B in 'high' and 'intermediate' endemic areas will depend upon universal immunization of infants with hepatitis B vaccine. This strategy acknowledges that infant immunization programs are the only functioning vaccine delivery systems in much of the world and that most infections occur during infancy and early childhood. Universal immunization of infants. perhaps followed by booster doses of hepatitis $B$ vaccine in early adolescence, eventually would eliminate the need for any other program to control sexual transmission of hepatitis B virus infections in these populations.

Targeting 'high risk' groups: In developed countries, where endemic rates are low but a large majority of cases occurs in sexually active young and middle-aged men and women, control strategies thus far have centred on identification of individuals with high risk sexual lifestyles for behavioral intervention and selective immunization with hepatitis B vaccine. Certain practical realities of this approach cast substantial doubt on whether it can ever succeed. In contrast to universal childhood immunization, precisely targeted programs to control sexually transmitted infections in adults must be designed around a thorough understanding of the epidemiology and natural history of the infection, known routes of transmission, and easily identifiable measures of risk. As noted here and elsewhere (11), in the case of sexually transmitted hepatitis $B$, much of this information is still lacking.

Even in homosexual men in whom the first and largest studies of the efficacy of hepatitis $B$ vaccine were performed, the vaccine has never been used successfully to control sexually transmitted hepatitis $\mathrm{B}$. Of an estimated 2.5 million persons who have received hepatitis $B$ vaccine in the United States, 85 to $90 \%$ were health care workers or institutionalized individuals who accounted for less than $5 \%$ of all reported cases of hepatitis B and who played almost no role in perpetuating endemic infection. This was mainly because a vaccine payment mechanism was identified which was driven by occupational health regulations and compensation/liability considerations. The failure to mount large scale hepatitis B control programs for homosexual men was multifactorial
TABLE 1

Numbers of new cases of gonorrhea and syphilis in homosexual men who attended the Denver Metro STD clinic, and of hepatitis B in homosexual male residents of Denver County 1982-90

\begin{tabular}{cccc}
\hline Year & Gonorrhea & Syphilis & Hepatitis B \\
\hline 1982 & 1809 & 138 & 22 \\
1983 & 1149 & 106 & 22 \\
1984 & 897 & 101 & 34 \\
1985 & 785 & 55 & 26 \\
1986 & 270 & 54 & 18 \\
1987 & 166 & 50 & 13 \\
1988 & 92 & 19 & 9 \\
1989 & 90 & 20 & 5 \\
1990 & 82 & 18 & 13 \\
\hline
\end{tabular}

STD Sexually transmitted disease

and included the high cost of the vaccine, an inadequate understanding of the long term complications of hepatitis B by both homosexual men and health care providers, the desire for sexual orientation anonymity, and the passive nature of most vaccination efforts.

Implications of AIDS: Owing almost entirely to major reductions in high risk sexual activity by homosexual men in response to the deadly AIDS epidemic, incidence rates of gonorrhea, syphilis and hepatitis B have fallen dramatically since the early 1980s (indicated by the representative experience of Denver, Colorado shown in Table 1). Over the first eight years of the AIDS epidemic, gonorrhea incidence declined by more than $95 \%$ and new cases of syphilis by $87 \%$. Incidence of hepatitis B infection has trended downwards too, but in a more moderate and inconsistent manner. Viewed another way, for the period 1982-85 homosexual men experienced $21 \%$ of all hepatitis B infections reported through the CDC's sentinel counties surveillance study, or more than one-third of all cases with a known source. By 1988 cases of hepatitis $B$ infection attributable to male homosexual exposure had declined to $7.2 \%$ of all cases (11).

Future hepatitis B control programs targeted at homosexual men must take these trends into account as well as other implications of a concurrent AIvS epidemic, ie, a homosexual man given hepatitis $B$ vaccine because of continuing high risk sexual activity will most likely become infected with HIV and die of AIDS before any of the long term complications of hepatitis B virus infection could occur. Cost effectiveness of a new vaccine initiative would be reduced further for men already infected with HIV as a consequence of lower antiHBs seroconversion rates and geometric mean titres, higher hepatitis B virus carriage rates (if 
infected during vaccination) (12), and possible stimulation of lymphocytes to produce HIV.

A countervailing argument accepts that fewer cases of hepatitis B infection can be prevented, but hypothesizes instead that those which are prevented will be far more important to reducing hepatitis $B$ virus endemic levels, especially if individuals who continue high risk sexual behaviour are at the same time rendered more infectious by HIV immunosupression. Recent trends in hepatitis B incidence in homosexual men and detailed case investigations do not currently support this concern and it would seem that limited funds for vaccination of homosexual men against hepatitis $\mathrm{B}$ would be better spent modifying residual high risk sexual behaviour which is the common denominator for all sexually transmitted infections, including AIDS.

Targeting 'high risk' heterosexuals: With the decline in the fraction of hepatitis $B$ infections attributable to homosexual men, attention has shifted to sexual transmission among heterosexual men and women, which according to the CDC's sentinel counties hepatitis study, comprised $26 \%$ of all cases in 1988 . This fraction is probably underestimated because a portion of the $37 \%$ with 'no known source' was undoubtedly sexually transmitted. Supporting evidence includes: an age-incidence distribution in cases with no known source suggestive of sexual transmission; a mutually exclusive hierarchical risk assignment method which favours parenteral drug use over sexual transmission; a restrictive case definition which requires, for heterosexual attribution, sexual contact with a known hepatitis B virus carrier or more than one sexual partner within six months; and a prevalence of hepatitis B virus markers of $19 \%$ in household and sexual contacts of hepatitis B patients with no identifiable source for infection, compared with 4 to $7 \%$ in the general population. It should also be recognized that the same case definition can result in classification errors in the opposite direction by designating cases as sexually transmitted which are not.

The actual routes of heterosexual transmission of hepatitis B virus as well as their relative and absolute efficiencies remain largely unknown. While the highest concentration of HBsAg is always found in blood, HBsAg also appears in saliva, semen, menstrual discharge, vaginal secretions, feces, urine and tears (10). Aside from blood, saliva is the vehicle with the greatest potential for nonparenteral transmission of hepatitis $B$ virus. A form of oral transmission could provide a common explanation for the high rates of infection observed in siblings and mothers of children with hepatitis $B$, in children fed premasticated food by HIV carrier mothers, in homosexual men who practice anilingus, and in heterosexual contacts of patients with hepatitis B.

To the extent that hepatitis $B$ virus infection in heterosexuals is transmitted by vaginal intercourse, the endocervix, endometrium, cervical ectopy and cervical inflammation caused by other sexually transmitted diseases provide biologically plausible exposed vascular targets for the low concentrations of hepatitis B virus found in semen. Also, 5 to $20 \%$ of women in developed countries occasionally practice anorectal intercourse, adding vascular rectal mucosa as another target. In the absence of high prevalence rates of genital ulcer disease, one might anticipate higher prevalence and incidence rates of hepatitis B virus infections in women.

In this regard, when gender-specific incidence rates are computed for one sentinel counties study period, respective rates for cases in heterosexual women and men are nearly identical - 3.0 and 2.9 per 100,000 , respectively - again raising the issue of whether another route of transmission (ie, oral) is needed to complete the infection loop back to men. As extensive oral contact often accompanies vaginal intercourse, this has been an exceedingly difficult issue to sort out. Indeed, most studies to date have not employed methodologies adequate to the problem of multiple colin earity of sexual risk factors.

The usual prevention measures such as using condoms, limiting the number of sexual partners, knowing one's sexual partners' infection status and partner notification may not be as effective as with other sexually transmitted diseases, given that: oral contact may be an important route of transmission; most heterosexual cases do not report large numbers of partners; fewer than $25 \%$ of cases can identify a known infected contact; and as many as $75 \%$ of adult cases may be subclinical and not come to medical attention.

For many of the same reasons, it is difficult to conceive of any effective control program based on timely identification of 'at risk' individuals for preor post exposure prophylaxis with vaccine and/or immune serum globulin. With post exposure prophylaxis the sexual partner to be notified and treated frequently turns out to be the unrecognized source of infection or has already been infected by the case. In addition, individuals at greatest risk increasingly are socioeconomically disadvantaged inner city minorities in whom sexual transmission of sexually transmitted diseases is at least partly driven by a vicious cycle of "sex for drugs'. Delivering routine preventive medicine of any kind to them has proved to be discouragingly problematic. 
Nonetheless, to examine the possibility that a sizeable proportion of all hepatitis B cases identified through Denver's participation in the CDC sentinel hepatitis study might previously have sought care at the city's sexually transmitted disease clinic and therefore might have benefited from a clinic-run vaccine program, the author compared cases of hepatitis B reported for the six month period January to June 1990 with the automated patient records of the sexually transmitted disease clinic for the period July 1988 to June 1990.

Although the sexually transmitted disease clinic sees an exceedingly high percentage of all sexually transmitted diseases reported from the city and county of Denver (estimated at 60 to $65 \%$ of the total), only seven of 67 cases (10.4\%) of hepatitis $\mathrm{B}$ had previously attended the clinic under the same name; three within one year and four more than one year prior to diagnosis. Beyond this, there is the well documented problem of compliance with follow-up instructions for sexually transmitted disease patients, even if the full three dose series could be offered free of charge. Follow-up is further compromised by the fact that 25 to $35 \%$ of patients provide insufficient or inaccurate names, addresses and/or telephone numbers.

Based upon one study from Worchester, Massachusetts, compliance may be even more problematic for intravenous drug users. When offered three doses of free vaccine in the setting of a community outbreak of fatal hepatitis D, only $15 \%$ accepted.

\section{REFERENCES}

1. Alter MJ. Heterosexual activity: A leading risk factor in the transmission of hepatitis B. Can $J$ Infect Dis 1991:2(Suppl A):PAGES?.

2. Jeffries DJ, James WH, Jefferiss FJG, et al. Australia (hepatitis associated) antigen in patients attending a venereal disease clinic. Br Med J 1973;ii:455-6.

3. Fulford KW, Dane DS, Catterall RD, et al. Australia antigen and antibody among patients attending a clinic for sexually transmitted diseases. Lancet 1973;ii:1470-3.

4. Szmuness W, Much I, Prince AM, et al. On the role of sexual behavior in the spread of hepatitis $B$ infection. Ann Intern Med 1975;83:489-95.

5. Schreeder MT, Thompson SE, Hadler SC, et al. Hepatitis B in homosexual men. Prevalence of infection and factors related to its transmission. J Infect Dis 1982:146:7-15.

6. Francis DP, Hadler SC, Thompson SE, et al. The prevention of hepatitis $B$ with vaccine. Report of the CDC Multicenter Efficacy Trial among homosexual men. Ann Intern Med 1982;97:362-6.

7. Hadler SC, Francis DP, Maynard JE, et al. Lorg-term immurlogenicity and efficacy of
Universal immunization: By a process of elimination, the only valid strategy for effective control of sexually transmitted hepatitis B in most developed countries is universal immunization of infants or young adolescents in school, or both. This strategy is needed to provide immunity from infection before risk-taking behaviour is acquired, and in persons with no known risk factors. Obviously, a program which only immunizes infants will require at least two decades before a significant control impact occurs, and a strong argument can thus be made for implementation of universal immunization of young adolescents.

Increasingly, preventive medicine is being organized around life cycle approaches and the adolescent life cycle has received high priority. School-based adolescent health clinics supported. by mandatory school immunization laws similar to those used to accomplish universal childhood immunization could offer 13- to 14year-olds booster doses of tetanus/diphtheria. rubella, measles, perhaps polio vaccines and primary immunization with hepatitis $B$ vaccine and, in the future, vaccines for other sexually transmitted infections such as HIV. Schools are particularly well suited to deliver comprehensive sexual health services because at ages 13 and 14 years almost all children are required to attend; dropping out is not yet a serious problem; and most sexually transmitted infection risk lies ahead. Whether such an approach is cost effective in a world of limited medical resources requires further analysis.

hepatitis $B$ vaccine. $N$ Engl $J$ Med 1986;315:209-14.

8. Villarejos WM, Visona KA, Gutierrez A,

Rodriguez A. Role of saliva, urine and feces in the transmission of type B hepatitis. N Engl J Med 1974;291:1375-8.

9. Reiner NE, Judson FN, Bond WW, Francis DI', Petersen NJ. Detection of asymptomatic rectal mucosal lesions and hepatitis B surface antigen at sites of sexual contact in homosexual men with persistent hepatitis B virus injection: Evidence for de facto parenteral transmission. Ann Intern Med 1982;96:170-3.

10. Judson FN. Epidemiology of sexually transmitted hepatitis B infections in heterosexuals: A review. Sex Transm Dis 1981;8:336-43.

11. Alter MJ, Hadler SC, Margolis ES, et al. The changing epidemiology of hepatitis B in the United States. Need for alternative vaccine strategies JAMA 1990;263:1218-22.

12. Hadler SC, Judson FN, O'Malley PM, et al. The outcome of hepatitis B infection in homosexual men and its relationship to prior human immunodeficiency virus infection. J Infect Dis. (In press) 


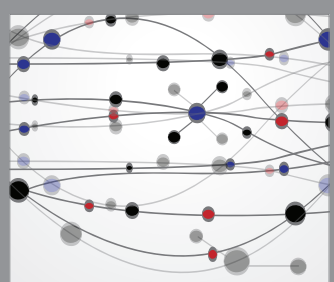

The Scientific World Journal
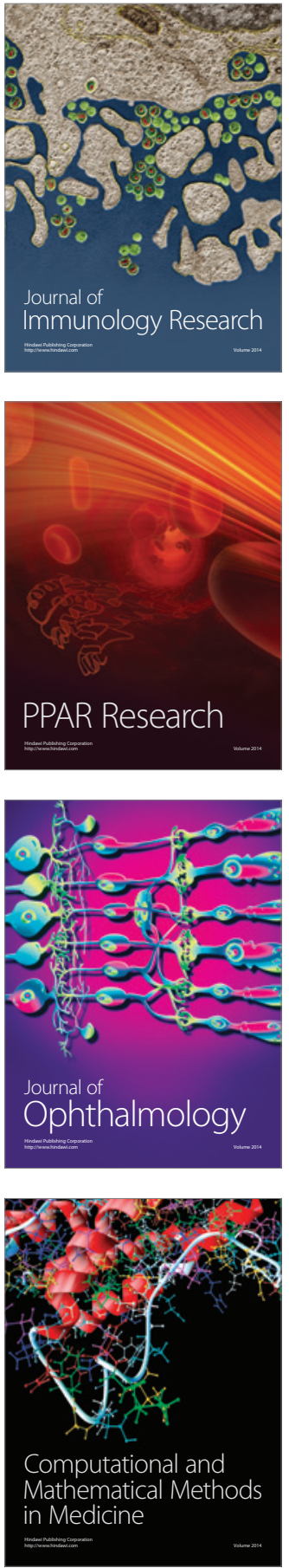

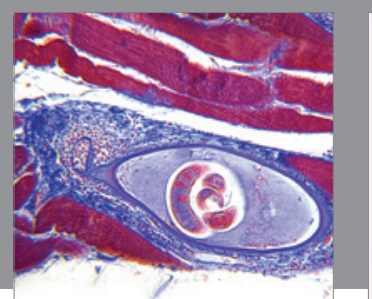

Gastroenterology Research and Practice

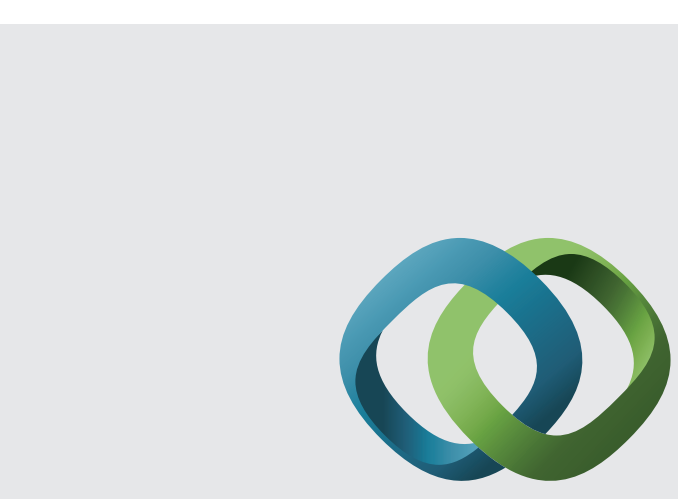

\section{Hindawi}

Submit your manuscripts at

http://www.hindawi.com
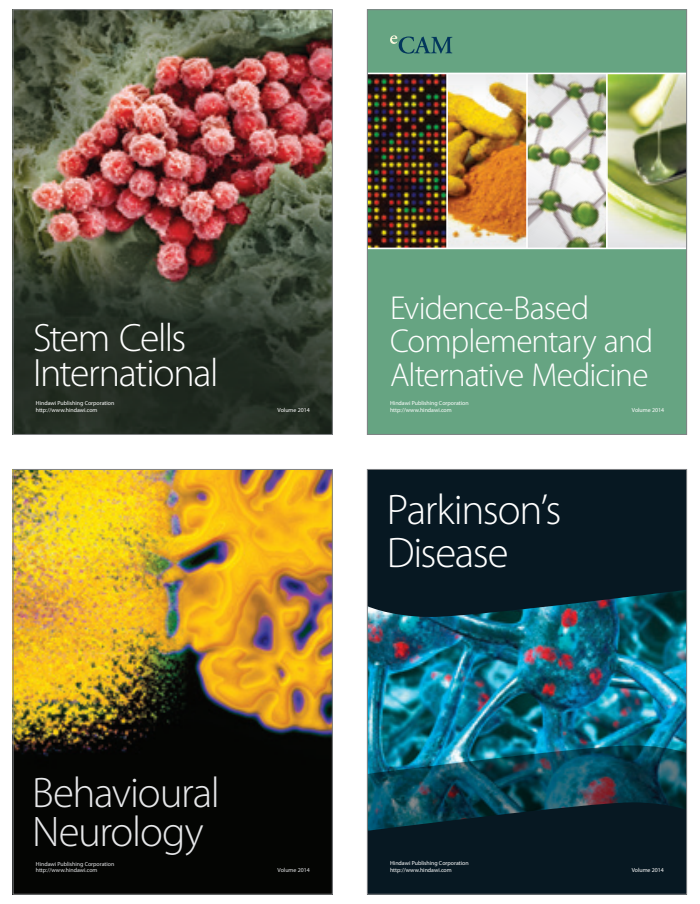
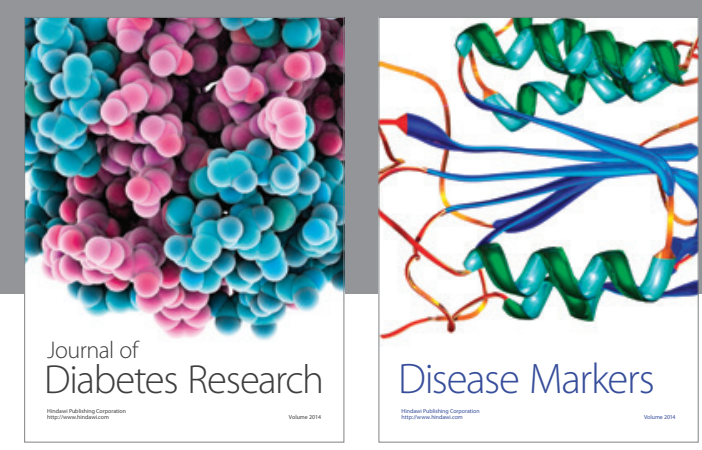

Disease Markers
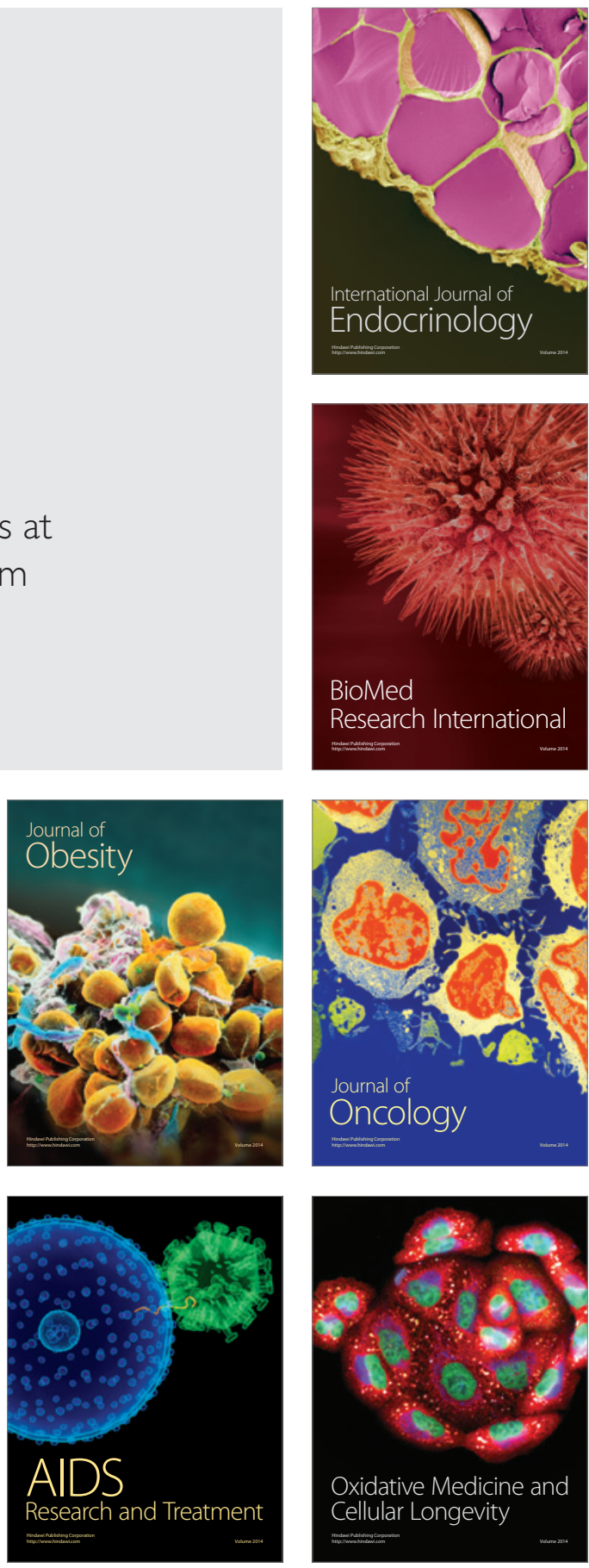